\title{
The Discussion of Modern Fine Design Standards
}

\author{
Lijuan Cao \\ Tianjin Polytechnic University, Tianjin 300384, China \\ E-mail: caolijuan006@yahoo.com.cn \\ Puming Huang \\ Tianjin Polytechnic University, Tianjin 300384, China \\ E-mail: huangpuming@yahoo.com.cn
}

\begin{abstract}
In the daily life we frequently refer to the topic "what is the good design?" Whether or not the design is fine, different people have different views, it does not have a constant evaluation criterion, and it can not be simply defined in one words. The idealized perfect design is hard to appears in the daily life, because different people regard the things in the different ways , regarding the different crowd, we are accustomed to look at "what is the fine design?" from the different angles. With the impact of the tide of globalization, more and more designs start to give up the design of a single strategy, and put into the embrace of diversity, its goal is to make the designs more comprehensive, macroscopic to control this kind of fine standard. At the crossroads of diversity, we cannot give the simple definition, so we only can look at whether this is the fine design from a wide range of perspective.
\end{abstract}

Keywords: Modern fine design, Standards, A wide range of perspective

\section{From artistic analysis of the design}

We would like to carry on the conceptual analysis before we first explore the artistic design concept analysis.

The word "design" has two meanings: As the verb, it refers to human activities; as the noun, is refers to the production of such activities. That we sum up the design as "human creative activities goal creative activity" should be based on suitable, appropriate and applicable principles. The so-called "suitable" has two aspects, one is the design proposal process, the other is the design demands, the conditions, limitations, and the evaluation criteria. The design must conform to the natural society's demand and human self-satisfaction, emphasize direction, particularity, individuality of designs, and enable the thing that has been designed to have more value. Therefore, any design is one kind of plan which makes the thing more systematic.

Art refers to a kind of form sum that the beauty rule and the aesthetics standard create of which people follow the ornamental value. The concept of modern art, has separated with "practical", and has association with "beautiful" intensively. The design artistry reflects that the design of things indicates one kind of beautiful experience, including feeling and emotion. The people create and design things in order to search for beauty, just as we seeks the strength that may shake the human heart and soul, so releasing the intrinsic pressure, also possibly is derived from the integrity of the demand. The Kant's empiricism philosophy thought that the beauty is nothing else but two kinds, namely beauty of freedom and interdependence to beauty while the latter contains the object of purpose, only when the object is consistent with its goal, it possibly becomes perfect. The design is one kind of special art, must follow the practical principle and esthetics and harmonious art creation rule, not only it takes the science and technology as the creation means, but also bases science and technology on implementation foundation.

The design of the spider-pressed lemon which is designed by a Famous designer Master Philips .Stark, afterwards it became one of Alerts most best-selling products, its artistic value was bigger than its practical value. Rather than it is a daily necessity, it looks like a sculpture art ware. Design artistry, is to enable our lives, the environment, the available items and the closest people around become more harmonious and more beautiful.(See Figure 1)

\section{From the design of functional analysis}

The functionality namely meaning purpose is most basic features of the design, which takes the function goal of the designed things as the starting point. According to the functionality of the design, it has been divided into three categories: Practical function, cognitive function and aesthetic functions. 


\subsection{The practical function}

The practical function is easy to understand, and it may directly meet human's some material needs through the design and human's matter energy exchange. The material properties are a foundation which the practical function produces.

\subsection{The cognitive function}

cognitive function which accepts the design of all kinds of information to stimulate and form overall cognition through visual, auditory, tactile and other sensory organs creating the corresponding concept and the representation, is one kind of mental function which the external form highlights. The cognitive function transmits "what it means" the information, is a good way to arouses emotion experience of the target population . The novel modeling, the personality colors, a unique logos express a unique use method.

\subsection{The aesthetic function}

Aesthetic function refers to the design of intrinsic and the external form arouses human's esthetic feeling, and causes one kind of the sympathetic response between "the thing and the human". It is a high-level spiritual function between the design and the human so as to meet human's esthetic needs.

The Dutch famous architecture and the industrial design Master Ritter Veldt's the red and blue chairs already become in the world art history the richest creativity and the most important work, although it is not extremely comfortable to be seated, but the original purpose of the designer was started from the functionality angle. Ritter Veldt's once like this has mentioned the red and blue chairs: "The structure should serve coordination between the various components in order to ensure the independence and integrity."(Figure 2)

The practical function, the cognitive function and the aesthetic function have became the design function of three kinds of types, the cognitive function are the practical function and the aesthetic function transitional stage. The aesthetic acquirement comes from the overall image of the function, as well as external constitution beauty of form and non-function elements of the emotional experience.

\section{3. from technical analysis of the design}

The natural sciences integrating the technology, has provided the more and more rich materializing methods for the design, even some of the technology have also changed the design of methods and concepts. The industrial revolution as a science and technology revolution once brought the huge change to the production of human life. Information technology age today, take a scientific and technical creativity means to guide and anticipate future design trends of the times.

\subsection{The design development always cannot leave the development of the human scientific and technological progress}

Throughout human history, we can see that the changes in human society, is the continual improvement of the social productive forces of history, and the continuous development of science and technology progress. From the moment that human started to transform nature, to conquer nature on, people began to find all to carry on "the design". Along with economical development, technical innovation and science revolutionary quietly changes, the design reflects people's thinking, the prevailing socio-economic structure, the level of technology development, as well as people's daily life way just like a mirror.

\subsection{The modern design development must be established in the modern scientific rational foundation}

The modern scientific rationality has two characteristics: One, the conceptualization, the other is symbol. The modern scientific rationality separates the concept, the symbol from the objective world thoroughly, and deducts the world with the concept and the symbol. Kant's contribution to the scientific rationality is that he emphasized human's main body activity function, raised the rational status. He thought that whether in scientific domain or in the moral domain, the rational necessity becomes all sources. Einstein pushed to the science development a new peak; the modern scientific rational spirit has much more development in his influence. In the methodology sense, the emphasis on rational logical thinking, the pursuit of knowledge can confirm the characteristics and the importance of accuracy trend .The modern scientific rationality in the strict logical rule, with the general nature of the thinking, will include all the possibilities.

"The modern design" is usually regard as "the function principle design". The main idea of the function is at the core function rather than form. The design process tends to take advantage of the science rationalization, to exploit market localization analysis, to analyze suitable crowd's localization as well as man-machine engineering, bionics and many discipline utilization. In the modern design methodology, the modern designs also start to utilize the induction and deduction, analysis and synthesis in a body, to focus on logical thinking method, the pursue design and to emphasize expression accuracy. Under the guidance of Rational thinking, the modern design will develop very well.

\subsection{The design is a carrier of the science and technology commercialization}

From the industrial age to the information technology time, with the rapid development of science and technology, designs as the method serve the capital increment, namely technical commercialization. No matter "taking the machine 
as the central design stage" or "commercialization of fashion design phase", the design all follows existing level of science and technology under the premise of the capital and commercialization operations. Design regarded as the market competition method, is a tool to stimulate consumption, serves in the capital multiplication, and is a carrier the science and technology commercialization too.

Under the instruction of science and technology ,no matter from the software and hardware design aspect, or from the outward appearance modeling, the brand culture and the marketing strategy, the Apple Company utilizes scientific rational systematized the design concept, and forges "the Apple Time".( Figure 3)

\section{4. from economic analysis of the design}

\subsection{Design is an important strategic economic development}

Li weite in the United States point out that the new competition does not lie in the product which the factory makes, but lies in the product packing, the service, the advertisement, the consultation, financing, delivers goods or the valuable thing that the customers like. The enterprise should seek the survival and the development in the competition and conforms to the design tidal current in the strategic concept, the management idea to the production method, the technical method, creates more economic benefits for the enterprises.

\subsection{Design and production and consumption are inseparable}

Design need to integrate the market, so we must balance the interests of principles --- balance and meet the demand between producers and consumers. The producers care the cost, the quantity of produces, the marketing profit and the market demand: The consumers are concerned about the reasonable price, the countenance good, the high quality and the good function of productions. The design must consider the producer and consumer's different demand so as to achieve one kind of "the balance". 1909 Germany work Association (DWB - - Deutscher Werkband) important target: Design high-quality materials, reasonable cost, and create a flawed product. The design must consider the material standardization, market supply and demand and so on. Production and consumption cannot be regarded in isolation, and the relationships between them are not opposite to each other but dynamic.

\section{General}

In summary, we should regard these characteristics correctly (design artistry, functionality, technical, economic) and the relationship between the design itself. On the "fine design", including on the design characteristic of the sensitive and accurate grasp and analysis, only the design has satisfied the particularity and the unique personality, then it has the value. The thorough research to different cultural communities is helpful to the understanding multi-dimensional designing, and this point has the special practical significance. The thing is the complex cultural powerful symbol. If the design were poured into the fine design characteristic diversification analysis, the design would certainly have the expressive force, and humanity's cultural world also can therefore become more richly colorful.

\section{References}

Liu, Guanzhong. (2006). SCIENCE OF HUMAN AFFAIRS. The Zhongnan University press. 1.

Zuo, Tiefeng. (2008). Strolls the product design artistic channel. China Ocean Press.

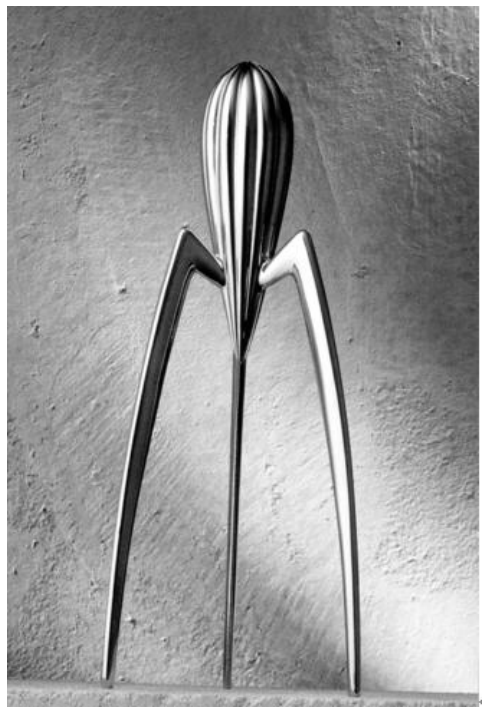

Figure 1. Philips .Stark Spider-pressed lemon 


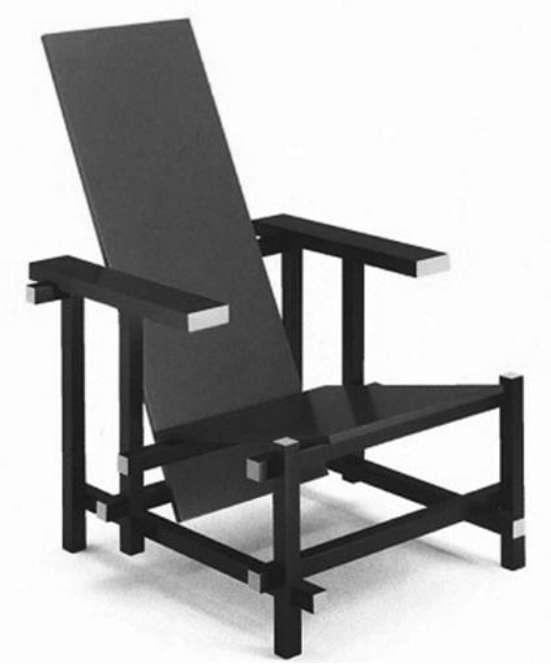

Figure 2. The red and blue chairs Teetered

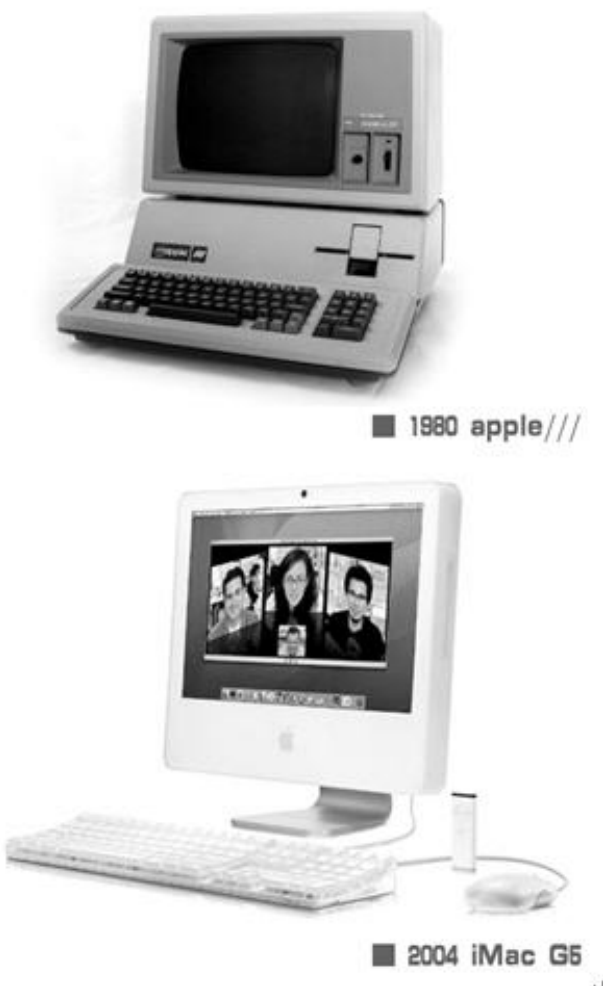

Figure 3. Apple Computer 